Objectives: To describe the long-term (5 year) efficacy and safety of APR monotherapy in DMARD-naïve subjects with active PsA from the phase 3 PALACE 4 study.

Methods: Subjects were randomised $(1: 1: 1)$ to receive placebo, APR $30 \mathrm{mg}$ BID (APR30), or APR 20 mg BID (APR20). At Week 16, subjects were eligible for early escape; placebo subjects were re-randomised to APR treatment, and APR subjects remained on their assigned dose. At Week 24 , all subjects remaining on placebo were re-randomised to APR. Double-blind treatment continued to Week 52 , with open-label APR treatment for up to 4 additional years.

Results: A total of 527 subjects were randomised and received $\geq 1$ dose of placebo $(n=176)$, APR30 $(n=176)$, or APR20 $(n=175)$. Among subjects randomised to APR30 at baseline, 45.5\% (80/176) completed the Week 260 visit. At Week 52, modified ACR20, ACR50, and ACR70 responses were achieved by $58.0 \%$, $29.8 \%$, and $15.5 \%$ of subjects receiving APR30, respectively, regardless of when APR was started (baseline, Week 16, or Week 24). Rates of improvement in PsA signs and symptoms and physical function were sustained up to Week 260 with continued APR30 treatment, including reduction rates in SJC of $84.8 \%$ and in TJC of $76.4 \%$ (table 1). At Week $260,65.8 \%, 39.0 \%$, and $20.3 \%$ of subjects achieved a modified ACR20, ACR50, and ACR70 response, respectively, and $71.2 \%$ of APR30 subjects with baseline enthesitis achieved a MASES of 0;95.1\% with baseline dactylitis achieved a dactylitis count of 0 . At Week $260,52.9 \%$ of subjects achieved a HAQ-DI MCID $>0.35,60.3 \%$ achieved a PASI-50 response, and $47.6 \%$ achieved a PASI-75 response (table 1 ). No new safety concerns were identified with APR up to 260 weeks. During Weeks $>208$ to $\leq 260$, the most common adverse event (AEs) among APR30-exposed subjects was nasopharyngitis $(6.9 \%)$. Serious AEs occurred in 5 APR30 subjects; serious infections were reported in 2 APR30 subjects (pelvic abscess and bacterial urinary tract infection), and no opportunistic infections were reported during Weeks $>208$ to $\leq 260$.

Abstract AB0905 - Table 1

\begin{tabular}{|c|c|}
\hline & Outcomes at Week 260 \\
\hline & $\begin{array}{l}\text { APR30 } \\
n=119^{*}\end{array}$ \\
\hline ACR20, $\mathrm{n} / \mathrm{m}^{\mathrm{S}}(\%)$ & $77 / 117(65.8)$ \\
\hline ACR50, $\mathrm{n}^{\mathrm{m}} \mathrm{m}(\%)$ & $46 / 118(39.0)$ \\
\hline ACR70, $\mathrm{n} / \mathrm{m}^{5}(\%)$ & $24 / 118(20.3)$ \\
\hline SJC, mean \% change & -84.8 \\
\hline TJC, mean $\%$ change & -76.4 \\
\hline MASES of $0, n / m(\%)^{\ddagger}$ & $47 / 66(71.2)$ \\
\hline Dactylitis count of $0, \mathrm{n} / \mathrm{m}(\%)^{11}$ & $58 / 61(95.1)$ \\
\hline HAQ-DI $(0-3)$, mean change & -0.38 \\
\hline HAQ-DI MCID $\geq 0.35, n / m(\%)$ & $63 / 119(52.9)$ \\
\hline PASI- $50, n / m(\%)^{\pi}$ & $38 / 63(60.3)$ \\
\hline PASI- $75, \mathrm{n} / \mathrm{m}(\%)^{m}$ & $30 / 63(47.6)$ \\
\hline
\end{tabular}

Conclusions: APR monotherapy demonstrated sustained response or improvements in PsA signs and symptoms, including SJC and TJC, enthesitis, dactylitis, physical function, and psoriasis in the population of subjects continuing treatment over 260 weeks. APR continued to demonstrate a favourable safety profile and was generally well tolerated.

Disclosure of Interest: A. Wells Grant/research support from: Celgene Corporation, C. Edwards Grant/research support from: Celgene Corporation; Pfizer, Roche, Samsung, Consultant for: Celgene Corporation, Pfizer, Roche, Samsung, Speakers bureau: Abbott, GSK, Pfizer, Roche, A. Kivitz Consultant for: Celgene Corporation, Speakers bureau: Celgene Corporation, P. Bird Grant/research support from: Celgene Corporation, B. Guerette Employee of: Celgene Corporation, N. Delev Employee of: Celgene Corporation, M. Paris Employee of: Celgene Corporation, L. Teng Employee of: Celgene Corporation, J. Aelion Grant/research support from: Celgene Corporation; AbbVie, Ardea Biosciences, AstraZeneca, BMS, Centocor, Eli Lilly, Galápagos, Genentech, GSK, Human Genome Sciences, Janssen, Merck, Mesoblast, Novartis, Novo Nordisk, Pfizer, Roche, SanofiAventis, Takeda Pharmaceuticals, UCB, Vertex Pharmaceuticals DOI: 10.1136/annrheumdis-2018-eular.3113

\section{AB0906 IXEKIZUMAB IMPROVES FATIGUE IN A SUBSET OF PATIENTS WITH PSORIATIC ARTHRITIS}

A.-M. Orbai ${ }^{1}$, D.D. Gladman ${ }^{2}$, H. Goto ${ }^{3}$, J. Birt ${ }^{4}$, C.-Y. Lin ${ }^{4}$, T.K. Kvien ${ }^{5}$. ${ }^{1}$ Johns Hopkins University School of Medicine, Baltimore, USA; ${ }^{2}$ University of Toronto, Toronto, Ontario, Canada; ${ }^{3}$ Osaka City General Hospital, Osaka, Japan; ${ }^{4}$ Eli Lilly and Company, Indianapolis, USA; ${ }^{5}$ Universitetet i Oslo Medisinske Fakultet, Oslo, Norway

Background: Psoriatic arthritis (PsA) is a chronic, systemic, inflammatory disease with both articular and extra-articular symptoms including joint pain, enthesitis, dactylitis, and fatigue. Fatigue is increasingly recognised as a priority symptom to patients and has been added to the PsA core set of outcomes for clinical trials. ${ }^{1}$ The best instrument to assess fatigue has not yet been defined.

Objectives: To assess fatigue improvement following treatment with ixekizumab (IXE), an anti-interleukin (IL)-17A monoclonal antibody, relative to placebo (PBO) in PsA patients.
Methods: In two phase 3 randomised controlled trials, patients naïve to and experienced with biologic disease-modifying antirheumatic drugs (SPIRIT-P1, SPIRIT$\mathrm{P} 2$, respectively) received subcutaneous PBO, ADA $40 \mathrm{mg}$ every 2 weeks (SPI RIT-P1 only; reference arm), or IXE 80 mg every 2 weeks (Q2W) or every 4 weeks (Q4W) after a $160 \mathrm{mg}$ starting dose for up to 24 weeks. At Week 16, all patients considered inadequate responders (IR) received rescue therapy. PBO and ADA patients were re-randomised (1:1) to Q2W or Q4W at Week 16 (IR) or Week 24; ADA patients underwent a washout prior to IXE treatment. Patients rated their worst level of fatigue during the past 24 hours at baseline, Week 4, 12, 16, 24, 32, and 52 on the 11-point Fatigue Severity Numeric Rating Scale (Fatigue NRS; not yet validated) where $0=$ no fatigue and $10=$ as bad as you can imagine. The minimal clinically important difference (MCID) was defined as an improvement $\geq 3$ on the Fatigue NRS.

Results: At Week 24 significantly more patients in both studies achieved fatigue improvements $>3$ on the Fatigue NRS with both IXE doses versus PBO (table 1; $\mathrm{NRI}$ ). When evaluating group level changes, statistically significant improvements on the Fatigue NRS were observed with both IXE doses versus PBO prior to Week 24 in both studies. At Week 24, significance was observed in the SPIRITP2 study only (table 1; MMRM). For patients who continued IXE treatment beyond Week 24, mean improvements on the Fatigue NRS persisted through Week 52 (table 1; MI).

\begin{tabular}{lccccccc} 
Table 1 & \multicolumn{1}{c}{ SPIRIT-P1 } & \multicolumn{3}{c}{ SPIRIT-P2 } \\
\hline & PBO & ADA & Q4W & Q2W & PBO & Q4W & Q2W \\
& $\mathrm{n}=106$ & $\mathrm{n}=101$ & $\mathrm{n}=107$ & $\mathrm{n}=103$ & $\mathrm{n}=118$ & $\mathrm{n}=122$ & $\mathrm{n}=123$ \\
\hline Baseline fatigue mean (SD) & 5.37 & 5.45 & 5.76 & 5.52 & 5.9 & 5.9 & 6.0 \\
& $(2.22)$ & $(2.34)$ & $(2.29)$ & $(2.44)$ & $(2.28)$ & $(2.48)$ & $(2.49)$ \\
& -1.3 & -1.5 & -1.6 & -1.9 & -0.7 & -2.0 & -2.1 \\
Change from baseline at & $(0.25)$ & $(0.24)$ & $(0.24)$ & $(0.24)$ & $(0.37)$ & $(0.35)$ & $(0.34)$ \\
Week 24 $^{\text {a }}$ & & & & & & $* *$ & $* *$ \\
LS mean (SE) & 19 & 28 & 35 & 34 & 6 & 33 & 36 \\
Number (\%) of patients & $(20.4)$ & $(32.9)$ & $(36.8)^{*}$ & $(40.5)^{*}$ & $(5.6)$ & $(30.8)$ & $(33.6)$ \\
achieving MCID at Week & & & & & & $* *$ & $* *$ \\
24 & & & -2.2 & -2.3 & & -2.2 & -2.2 \\
Change from baseline at $^{\mathrm{b}}$ & & & $(0.28)$ & $(0.28)$ & & $(0.24)$ & $(0.27)$ \\
Week 52 $^{\mathrm{d}}$ mean (SE) & & & & & & &
\end{tabular}

${ }^{\text {a }}$ Mixed models repeated measures (MMRM) analysis was used to calculate change from baseline.

${ }^{\mathrm{b}}$ Analysis of patients with Fatigue NRS $\geq 3$ at baseline. SPIRIT-P1: PBO, $n=93$; ADA, $n=85$; Q4W, $n=95$; Q2W, $n=84$. SPIRIT-P2: PBO, $n=108$; $44 W, n=107$; Q2W, $n=107$.

CNonresponder imputation (NRI) was used to impute missing data based on logistic model.

${ }^{\mathrm{d}}$ Multiple imputation (MI) was used to impute missing data.

${ }^{*} \mathrm{p}<0.05$ vs $\mathrm{PBO} ;{ }^{* *} \mathrm{p}<0.001$ vs $\mathrm{PBO}$

Conclusions: In a subset of PsA patients, clinically meaningful improvements in fatigue level were observed following IXE treatment. Fatigue improvement persisted with up to 1 year of IXE treatment.

\section{REFERENCE:}

[1] Orbai, et al. Ann Rheum Dis. 2017;76:673-80.

Disclosure of Interest: A.-M. Orbai Grant/research support from: Abbvie, Celgene, Eli Lilly, Horizon, Janssen, Novartis, Pfizer, Consultant for: Eli Lilly, Janssen, Novartis, Pfizer, UCB, D. D. Gladman Grant/research support from: Abbvie, Amgen, Celgene, Janssen, Novartis, Pfizer, UCB, Consultant for: Abbvie, Amgen, BMS, Celgene, Eli Lilly, Janssen, Novartis, Pfizer, UCB, H. Goto Grant/research support from: Abbvie, Eli Lilly, Kyowa Hakko Kirin, Consultant for: Abbvie, AYUMI Chugai, Eisai, Eli Lilly, Janssen, Maruho, Mitsubishi Tanabe, Novartis, Pfizer, Takeda, Speakers bureau: Abbvie, AYUMI, Chugai, Eisai, Eli Lilly, Janssen, Maruho, Mitsubishi Tanabe, Novartis, Pfizer, Takeda, J. Birt Shareholder of: Eli Lilly and Company, Employee of: Eli Lilly and Company, C.-Y. Lin Shareholder of: Eli Lilly and Company, Employee of: Eli Lilly and Company, T. K. Kvien Grant/ research support from: AbbVie, BMS, MSD, Pfizer, Roche, UCB, Consultant for: AbbVie, Biogen, BMS, Boehringer Ingelheim, Celgene, Celltrion, Eli Lilly and Company, Epirus, Hospira, Merck-Serono, MSD, Mundipharma, Novartis, Oktal, Orion Pharma, Hospira/Pfizer, Roche, Sandoz, UCB

DOI: 10.1136/annrheumdis-2018-eular.2130 